\title{
The Characterization, Causes and Countermeasures of Mental Poverty in Rural Areas of Western China
}

\author{
Kang Zhao ${ }^{1, a^{*}}$ Kang You-li ${ }^{2, b}$ \\ ${ }^{1}$ School of Education, Research Center for Mental Health Education, China West Normal University, Nanchong, \\ Sichuan, China \\ ${ }^{2}$ Psychological Counseling Center for University Students, China West Normal University, Nanchong, Sichuan, \\ China \\ a*kangzhao168@126.com \\ ${ }^{b}$ kangyouli001@126.com
}

\begin{abstract}
Mental poverty has led to the lack of spiritual motivation and intellectual support for poverty-stricken groups in western China, which has seriously hindered the pace of rural economic development in western China and the overall effectiveness of precise poverty alleviation. The problems of mental poverty are mainly characterized by backward ideas, lack of ideals and beliefs, serious distortion of values, ignorance of the spiritual world and lack of innovative spirit. The emergence of mental poverty is the result of a combination of plenty of factors such as extreme material poverty in the rural poverty-stricken areas, outdated thinking, serious lack of cultural education, poor mode of social poverty alleviation and insufficient endogenous motivation for self-development. To thoroughly solve the problem of mental poverty in rural areas of western China, we should focus on reshaping the positive and enterprising consciousness of the mentally impoverished subjects, establish a poverty alleviation and relief model that will effectively stimulate the endogenous motivation of the poor groups, strengthen the cultural education and scientific popularization of the poor groups, strive to enhance the soft power of rural culture, attach importance to the advanced demonstration and model guidance of the poor groups, give full play to the regional advantages of the rural areas in western China and the positive role of the non-governmental clan groups, help the rural poor groups in western China get rid of poverty and become rich at an early date, and promote the precise poverty alleviation work in western China to achieve the expected goal.
\end{abstract}

Keywords: western China, mental poverty, precise poverty alleviation

\section{西部地区农村精神贫困问题表征、成因与对策}

\author{
康钊 $1, \mathrm{a}^{*}$ 康有黎 $2, \mathrm{~b}$
}

\author{
${ }^{1}$ 西华师范大学教育学院 南充四川中国 \\ 2 西华师范大学大学生心理咨询中心 南充四川中国 \\ a*kangzhao168@126.com \\ ${ }^{b}$ kangyouli001@126.com
}

\section{摘要}

精神贫困导致西部地区农村贫困群体缺乏脱贫致富的精神动力和智力支持，严重阻碍着西部地区农村经济发 展的步伐和精准扶贫工作的整体成效。群体精神贫困主要表现为思想观念落后、理想信念缺失、价值观严重扭 曲、精神世界愚昧落后以及缺乏创新精神等问题，其产生是农村贫困地区物质方面的极度贫困、思维观念陈旧 落后、文化教育严重缺失、社会扶贫救助模式欠佳及自身发展内生动力不足等多种因素综合作用的结果。要彻 底解决西部地区农村精神贫困问题，应当注重重塑精神贫困主体的积极进取意识，建立有效激发贫困群体内生 动力的扶贫救助模式, 加大对贫困群体的文化教育和科学普及力度, 努力提升农村文化软实力, 重视对贫困群 体的先进示范和榜样引导，充分发挥西部地区农村的地缘优势和民间宗族群体的积极作用，助推西部地区农村 
贫困群体早日脱贫致富, 促成西部地区精准扶贫工作达成预期目标。

关键词: 西部地区，精神贫困，精准扶贫

\section{1. 引言}

随着我国精准扶贫工作的全面落实和积极推进, 当前已经进入脱贫攻坚的关键时期, 许多农村贫困群 体现已彻底摆脱贫困状态并逐渐走上小康发展的道 路。在惊叹我国精准扶贫工作取得巨大成就的同时, 我们还必须清楚意识到由于诸多原因造成西部农村 地区的贫困状态还未完全消除，特别是当前西部农村 地区的精神贫困问题日益凸显更是阻碍贫困对象脱 贫致富的一大难题。西部地区农村部分贫困对象摆脱 贫困状态的主体意识与内生动力不足, 脱贫过程中 “等、靠、要” 依赖思想极其严重, 将原本应是积极 促进农村贫困对象主体 “我要脱贫” 异化为 “要我 脱贫” , 部分贫困对象甚至形成不愿脱贫的扭曲心理, 这必然从整体上严重影响我国扶贫攻坚工作的进程 和效果。认真审视并科学认知西部地区农村精神贫困 问题及其成因，积极探索消除精神贫困问题的路径对 于全面实现西部地区农村贫困对象脱贫致富具有重 要的现实意义。

\section{2． 西部地区农村精神贫困问题的内涵及表征}

\section{1. 农村精神贫困问题的内涵解读}

何谓精神贫困? 单从字面上理解, 精神贫困自然 应当指个体或群体在精神层面上的贫乏和若困状态。 余德华 (2002) 认为精神贫困是指由于多种发展障碍 和制约因素而造成的某一社会群体或个体在其思想 道德素质、文化知识水平、价值观念与取向、风俗习 惯、思维意识以及行为方式等方面落后于社会主要物 质生产方式, 由此形成影响其物质生活资料获取和精 神生活需求满足的生存状态 [1]。吴稼稷 (2002) 认为 精神贫困是指人类由于主体层面的精神文化不能充 分满足其基本需要而导致主体自身存在的意识行为 偏差状况, 诸如主动意识相对缺乏、生活目标迷失、 情感极其枯竭、价值观念陈旧、过分追求低级趣味以 及沉湎于旧有习俗等问题 [2]。杭承政和胡鞍钢 (2017) 认为精神贫困的本质是个体志向失灵和行为失灵, 把 精神贫困概念界定为个体志向缺乏、信念消极和行为 决策非理性等行为特征 [3]。还有不少研究者将精神 贫困和文化贫困两个概念等同, 但我们认为文化贫困 可能更多表现为文化素养水平低下, 科学文化知识缺 乏以及文化娱乐活动极度贵乏等特征, 与精神贫困概 念虽有交叉, 但二者不能完全等同混用。尽管不同学 者对精神贫困这一概念界定不一, 但从本质上说, 精
神贫困是指社会群体或个体由于社会历史或主体自 身等因素导致其思维认知、精神状态、价值取向和行 为模式等不能充分满足社会现实生活需求, 落后于社 会主流生产生活水平并与当前社会发展不相适应甚 至完全抵触的精神状态。

应当说, 相对于当前社会发展进步对个体或群体 在精神层面的要求而言, 精神贫困可看作是一种更高 层次的综合性社会问题，特指个体或群体在其主体意 识观念与价值理性范畴等方面表现出来的贫乏或缺 失状态。也就是说, 我们所说的精神贫困是指特定主 体的理想信念、价值观念、道德品质及文化习俗等精 神生活状态不能充分满足当前社会现实生活的基本 需要, 并且表现出与社会主要物质生产方式不相符合 或者较为落后的状态。从基本形态上看, 贫困既有绝 对形态, 亦有相对形态, 由此同样可将精神贫困划分 为绝对精神贫困和相对精神贫困两种状态。绝对精神 贫困是指某一社会群体或个体因为物质生活的极端 贫困而导致主体文化教育严重缺失、价值观念陈旧滞 后、精神生活单调贫乏及思维模式保守傈化等问题, 由此造成自身生存与适应能力极其低下; 相对精神贫 困是指某些特定主体的教育理念、文化素养、道德品 质与价值观念等精神状态并未随着自身物质生活水 平的极大改善而出现相应的变化与提升, 与社会精神 文明建设发展主流方向存在一定偏差或落后于社会 整体发展水平。

\section{2. 西部地区农村精神贫困问题举隅}

精神贫困是相对于物质贫困而言的贫困状态, 物 质贫困是能看得到的现象, 精神贫困是隐含在物质和 个体行为当中的现象。从一定程度上说, 个体精神贫 困状态的形成既是物质方面极度贫困的发展结果, 反 过来主体本身的精神贫困又是物质贫困长期存在的 重要原因。由此, 必须正确对待精神贫困这一重大问 题。精神贫困的表现形式多种多样, 许多学者的研究 都证实贫困群体身上精神贫困现象的客观存在, 综合 众多学者的研究, 结合对西部地区农村精神贫困问题 的调查分析, 我认为精神贫困问题主要表现在以下三 大方面。

第一, 理想信念缺失, 价值观严重扭曲, 对自身 发展动力认知不足, 安于贫困、消极无为的精神状况 导致脱贫致富过程中的依赖心理极其严重。通过对西 部贫困地区的调查表明, 部分农民的贫困与其缺乏科 学的理想信念、消极应对和懒惰行为密不可分。相当 
部分贫困群体满足于当前的极小成就，还有部分贫困 农民安守贫困而无所作为, 缺失发家致富的强烈意愿 部分贫困农民 “等、靠、要”思想比较严重，过分依 赖政府或者对口帮扶单位送钱给物，依靠日常救济来 维持基本生活。有些地方甚至还出现不愿通过自己的 努力奋斗早日脱贫致富, 反而全力争取贫困户或救济 帮助的怪象, 形成 “穷占便宜富吃亏”的不正常心态, 导致部分贫困对象因此而缺乏脱贫致富的动机和信 心, 甚至于不加尝试地主动放弃一些有利于脱贫致富 的行为。通过劳动发家致富的理念极度弱化, 脱贫过 程中致富伦理缺失, 对法律法规认识不足, 个人享乐 主义盛行, 平均主义思想严重。部分贫困群体常常表 现为 “人穷志短” , 存在着明显的短视行为, 容易受 外界诱惑而更看重当前的 “蝇头小利” , 缺乏上进心 和积极行动的力量源泉。

第二，观念陈旧落后，思想保守僵化，陈规陃习 普遍存在, 封建迷信思想有所抬头, 精神世界的愚昧 落后导致脱贫致富中不思进取而逆来顺受的消极心 理状态。西部农村贫困地区主要分布在较为偏远的山 区或少数民族聚居地, 自然环境条件较为恶劣, 多数 地方交通不便且经济相当落后, 当地群众长期生活在 比较狭险封闭的社会环境中, 受几千年小农经济的传 统思想影响, 过分依赖靠天吃饭的耕种模式, 世代重 复祖辈的生产和生活方式, 思维观念保守落后, 陈规 陃习普遍存在, 因循守旧而不愿改变自己或积极主动 接受新生事物。特别是过分相信 “生死有命, 富贵在 天” 的传统宿命论思想, 对科学运用自己的智慧和凭 借自己勤劳的双手去改变自身贫穷落后的生存状况 缺乏基本的认知和实践。个体精神世界的保守偪化与 愚昧落后必然导致个体主动寻求发展的动力严重不 足。部分贫困群众世代遵循祖辈沿袭下来的简单农耕 劳动方式, 宁愿固守乡土过着极端贫困的生活, 仅仅 满足于解决日常温饱问题, 饮食结构极其简单, 主观 精神世界的极度落后导致他们缺少进取心理而逆来 顺受, 整体生活质量水平极低。

第三, 对文化教育改变贫穷落后面貌的认知不足, 教育投入不够且接受教育的年限较短, 科学文化水平 素养较低, 文化娱乐活动方式单调, 精神生活的极度 贫乏导致精神空虚而极易滋生事端。西部农村贫困地 区文化教育事业的极度落后和贫困主体自身生存发 展能力的严重缺失必然在很大程度上阻碍农村经济 发展的步伐, 极其传统落后的生产和生活方式同样严 重影响着西部农村贫困地区市场经济体制建设的进 程 [4]。西部地区农村贫困群体的教育和智力开发不 足, 导致科学文化水平素养极低、摆脱贫困的文化自 信不足、文化产业理念陈旧、文化产业发展要素基础 薄弱等诸多问题。正因为对文化教育改变自身的贫困 状态认知不足, 西部贫困群体在教育方面的投入严重 不足, 接受教育的时间极短, 文化教育发展进程极其 缓慢。同时, 深受读书无用论思想影响, 农村学校入 学率较低且辍学率较高, 由此出现贫困的代际传递也 就在所难免。西部地区农村贫困对象精神文化生活极
其单调贫乏, 看电视可能是他们主要的娱乐活动, 其 他文化活动几乎没有, 难以满足各类人群文化精神生 活的需要。精神生活的极度贫乏导致西部地区农村贫 困群体精神空虚, 部分人整天沉迷于奢博、酗酒、吸 毒或打架斗殴, 甚至走上违法犯罪的道路。

\section{3. 西部地区农村精神贫困问题的成因分析}

\section{1. 经济发展的严重滞后导致物质方面的极 度贫困状态是西部地区农村精神贫困问题产 生的根本原因}

从一定程度上说，精神贫困问题是物质贫困状态 的直接后果和人文表现, 因此, 我们同样可将西部地 区农村物质方面的极度贫困状态看作是农村精神贫 困问题产生的根本原因。因为物质状态决定着精神状 态, 物质方面的贫穷极大可能导致精神上的贫穷。通 常情况下, 个体如果连基本的物质生活需要都不能得 到满足的话, 他自然很难要求满足精神文化生活层面 的需要。西部地区农村生产力水平较为低下, 物质财 富极其贵乏，由此造成精神生活的空虚与贫乏也就难 以避免。物质方面的极度贫困不仅使西部地区农村贫 困群体可能因此而丧失充分享受基本的物质财富的 权利, 同时也同样可能使他们在追求精神财富享受时 大打折扣。也正是因为物质方面的贫困导致诸多问题 和发展限制，西部农村贫困地区的教育资源同样十分 稀缺和贵乏，这就必然导致贫困群众接受教育的基本 权利遭受损害, 这又可能在一定程度上加剧西部农村 地区的贫穷落后状态。同时，经济的落后和物质的贫 困状态导致西部农村贫困地区的财政维持与基本支 出都相当困难，更难以满足当地人民群众的公共文化 服务需求。而因经济状况所致西部地区文化教育资源 的相对缺失, 又必然导致贫困群众只能依靠家庭的世 代相传和社会影响渗透来实现简单的知识接受与文 化传承。因此，西部农村贫困群众所接受的思想观念 和文化教育难以摆脱其固有的极其狭险和封闭的生 活模式的影响，陈旧滞后的主体观念和简单落后的生 活生产方式必然严重阻碍着他们实现真正意义的脱 贫致富。此外, 还有一点我们不能忽视, 那就是西部 农村贫困地区的致富道路底子相对较薄，同物质生活 条件相对富裕的群众相比，西部贫困群众可能付出同 等甚至更多的艰辛和努力但自己所获得的财富或许 更少，这也会严重挫伤他们努力摆脱困境走上致富道 路的主体积极性。

\section{2. 相对滞后的生活观念和僵化陈旧的思维 方式是西部地区农村精神贫困问题产生的直 接原因}

相对滞后的生活观念和僵化陈旧的思维方式极 易导致西部地区农村人口精神贫困代际相传，这是我 们探讨西部地区农村精神贫困这一问题时必须考虑 的重要因素。前面已经提到, 西部地区贫困群体长期 
生活在极其封闭落后的生活环境之中，世世代代重复 着祖辈流传下来的简单生产劳动和生活方式, 劳动生 产率极其低下，思想观念难以跟上时代节奏，滞后陈 旧的思维意识又可能在一定程度上固化他们在精神 方面的贫困, 这种落后观念和陈旧思维导致精神贫困 现象在西部地区贫困群众中代际相传。由此造成西部 地区农村贫困对象发展动力严重不足，对于通过勤劳 致富去追求自己的幸福生活缺乏足够的激情和冲动, 其主体意识未能完全觉醒, 缺乏敢想敢干和勇于拼搏 的精神, 创新创造性思维缺失, 主体积极进取发展意 识观念退化, 导致贫困对象缺乏脱贫致富的积极动力 而过度依赖政府救济和社会援助。在顺境时他们小富 即安, 极易为蝇头小利沾沾自喜; 在逆境时他们看不 到希望, 要么消极被动逆来顺受, 或者听天由命随遇 而安, 更多地把自身命运的改变寄托于上天或者过分 依赖于国家的赐予, 鲜有自己积极的行动和抗争 [5]。 同时, 受流行的拜物主义思想及不良媒体的舆论导向 等因素的影响, 他们的价值取向发生改变。再加上西 方不良文化的大作渗透, 劳动光荣与勤劳致富等中华 民族优秀传统思想被弱化, 部分贫困人口的生存理念 畸形发展, 不再尊重劳动与热爱劳动, 幻想不劳而获 和一夜暴富, 甚至为此不惜以身试法而走上违法犯罪 的道路, 严重阻碍西部地区农村贫困对象脱贫致富的 发展进程, 并在一定程度上对社会的和谐与稳定造成 影响。

\section{3. 文化教育的严重缺失和精神生活的极度 贾乏是西部地区农村精神爸困问题产生的主 要原因}

文化教育的严重缺失和精神生活的极度贵乏必 然极大地阻碍西部地区农村经济与社会发展的步伐, 自然成为西部地区农村贫困问题产生的主要原因。我 们知道科技和教育是促进社会发展的重要动力源泉, 如果一个地区的劳动者所接受的文化教育程度越高, 那么他们的文化水平和相应的生产生活技能自然也 相对较高, 同时这个地区的经济发展水平也必定因此 而大大提高。也就是说，农村地区的教育水平的高低 与其贫困状况呈负相关关系, 教育水平越低的地区, 其贫困发生率自然相对会高一些。西部地区农村贫困 人口接受教育的年限相对较短, 教育普及率不高, 文 盲半文盲的比重较高。再加上西部地区学校教育教学 设施较为落后, 师资力量严重不足, 教育的缺失和文 化知识的贵乏致使西部地区贫困群众不仅普遍 “缺 智” 而且更多表现出 “缺志” 等特点。正因为农村社 会经济发展水平与劳动者接受教育的程度和文化水 平的高低之间存在着较为密切的关系, 农村贫困对象 接受教育机会的缺失不仅导致西部农村地区贫困对 象文化水平普遍偏低, 缺乏适应社会生活所需要的基 本劳动与生存技能, 在一定程度上丧失通过自己的努 力去创造物质和精神财富的能力, 而且导致西部地区 贫困群众主体目光短浅而不思进取, 思想观念的凝固 滞后等精神贫困现象, 这些问题的出现必然反过来进
一步加重其物质贫困的严重程度, 由此陷入恶性循环 的困境之中。

\section{4. 采用传统的救济扶贫方式导致贫困主体 脱贫内生动力不足是西部地区农村精神贫困 问题产生的重要原因}

随着我国精准扶贫工作的深入推进, 西部地区农 村扶贫攻坚工作取得巨大成就，许多农村贫困对象逐 渐走上了脱贫致富的发展道路。但我们同样应当清楚 地认识到西部地区农村贫困问题并未完全消除, 部分 贫困对象进取意识不强甚至于消极应对, 特别是传统 的救济扶贫方式在某种程度上可能反而助长了农村 贫困对象精神贫困问题的形成。我国各级政府和相关 部门在一个比较长的时期内多采用 “输血” 式救济 扶贫, 直接给西部地区贫困群众赠送各种生活必需品 或钱财, 不仅没有真正解决西部地区贫困群众的精神 贫困问题，甚至于在一定程度上助长了他们的 “等、 靠、要” 思想。有些贫困群体甚至于不愿意主动努力 摘下贫困的帽子, 反而消极被动就地坐等国家和社会 各部门的救济帮助, 根本无法斩断贫困之根反而滋生 出更多的社会问题。特别是西部地区农村贫困对象长 期生活在相对封闭的生活环境中, 基本依靠传统的自 给自足经济模式, 固守着较为简单落后的生产与生活 方式, 思想保守狭险且目光短浅, 因此他们普遍缺乏 与市场经济要求相适应的竞争意识和效益观念等 [6]。

\section{4. 西部地区农村精神贫困问题的对策探讨}

从某种意义上说, 西部地区农村贫困对象的精神 贫困问题比物质贫困更为可怕，因为物质贫困问题可 能只是短期的、暂时的, 但精神贫困问题则可能伴随 和困扰农村贫困对象整个人生, 同时处理不好还可能 出现贫困现象的代际传递, 并可能使农村贫困群体逐 渐消磨其斗志而彻底失去积极面对贫困问题和勇于 与命运抗争的精神动力。积极探索有效应对西部地区 农村精神贫困问题的对策是时代的迫切呼唤。

\section{1. 积极培育和践行社会主义核心价值观， 弘扬劳动无尚光荣的优良传统和树立勤劳致 富的发展理念, 重塑贫困主体的进取意识, 这 是消除西部地区精神贫困的思想基础和精神 支撑}

全力帮助西部地区贫困群体彻底摆脱贫困是国 家和社会各部门需要努力解决的要事, 但同时也是贫 困户自己的大事。西部地区部分贫困群体不思进取、 缺乏脱贫动力, 这是客观存在的事实。我们必须重视 强化对西部地区贫困群体的思想教育引导工作, 积极 培育和努力践行社会主义核心价值观, 特别要重视顺 应当前农村时代发展特点, 建立高度完善和科学有效 的农村扶贫激励机制，全面激发西部地区农村贫困对 象全力脱贫致富的志向和热情。西部地区精准扶贫实 
践中要大力弘扬中华民族勤劳勇敢的优良传统, 帮助 农村贫困对象牢固树立勤劳致富的发家理念，特别是 要在实践中真正破除部分贫困群众的消极等待思想, 帮助贫困对象充分实现主体价值观念的重塑, 全面培 养他们自强不息的奋斗精神，将贫困对象脱贫致富的 主动性和积极性充分调动起来, 真正激发贫困对象主 体脱贫致富的内在动力。传统扶贫工作中实施简单的 物质帮扶措施并不能够真正激发西部地区广大贫困 群众努力摆脱贫困的主体意识, 反而可能因此而滋生 少数贫困群众的消极等待思想, 甚至在某种程度上让 其精神贫困现象更加严重。因此, 新时期提升西部地 区贫困主体的积极进取意识, 促进其能力发展并激发 其内生动力成为消除精神贫困的重要思想基础。消除 精神贫困重在激发个体的内生动力与活力, 因此精神 扶贫应当侧重于个体的精神空间的开拓与发展。实践 中可通过强化思想教育因素激发与提升西部地区农 村贫困群众积极脱贫的主体意识与内在活力, 将针对 他们的扶贫工作与对其进行 “扶志” 和 “扶智” 高 度结合, 强调塑造和提升个体的生存能力来培育脱贫 内生动力 $[7]$ 。

\section{2. 重视中华民族传统文化精神的传承与发 展, 全面树立文化自信思想, 努力提升农村文 化软实力，这是消除西部地区精神贫困的文化 基础}

所谓文化自信，是指一个国家或民族对自身所主 导和拥有的文化内核及其价值的充分肯定, 也是对自 身文化独具的品质特征与旺盛生命力的高度体认, 更 是对自身文化未来不断发展所持有的坚定信念。没有 高度的文化自信和文化的繁荣兴盛, 就无法真正实现 中华民族的伟大复兴 [8]。我们应当重视对中华民族 优秀传统文化精神的传承与发展, 要重视对包括人们 的风俗习惯、思维方式和价值观念等在内的传统文化 进行全面改造和不断创新, 以此促进我国精神文化方 面的建设并消除西部地区农村精神贫困问题。实践中 西部地区农村文化发展应当注重通过改变传统的生 产和生活模式, 借助对教育模式的改造来彻底改变贫 困地区的教育落后情况, 提高农村贫困群体的整体素 质, 实现价值取向的正确回归与全面提升, 从根本上 改变西部地区贫困人口的精神面貌, 使其焕发出自强、 自信的进取精神。针对西部地区农村精神贫困问题进 行的精神扶贫工作, 就是要通过科学和系统的方法积 极主动地干预贫困对象的主观精神世界, 充分调动贫 困对象脱贫致富的主观能动性, 其本质就是要通过整 治内因提高被扶贫者脱贫致富的内生动力来消灭贫 困文化 [9]。正因为西部地区农民科学文化水平相对 较低及农村公共文化产品相对贵乏等问题客观存在, 我们必须重视积极推进农村文化基础设施建设进程, 优化各种文化资源的分配机制, 特别是要大幅增加对 农村文化基础设施建设的经费投入，促进农村地区文 化的可持续发展。同时, 我们必须重视加强对传统文 化的深刻理解和深入反思, 结合时代精神积极对传统
文化进行改造与重构, 注重贫困对象个体的全面发展 以充分实现对主体时代精神的重塑, 形成适应现代生 活需求的价值观念和文化素养, 积极推进西部贫困地 区文化发展与进步并以此提升农村文化软实力, 这样 才能从根本上全面消除西部地区农村贫困群体的精 神贫困现象。

\section{3. 大力促进西部地区经济发展, 建立可靠 有效的扶贫救助模式，营造良好的生存环境， 这是消除西部地区精神贫困的重要物质基础}

大力改善西部地区农村贫困对象的经济状况并 努力创造较好的物质条件, 这是消除西部地区农村贫 困对象精神贫困的重要基础和根本出路。努力发展生 产积极提升西部农村地区的生产力水平，向社会提供 丰富的物质产品满足贫困群体的基本需要, 是解除和 治理西部地区精神贫困的基础。西部地区的精神扶贫 工作需要认真做好顶层设计工作, 尤其要解决扶贫过 程中各主体的激励不相容问题。西部地区农村贫困人 口 “等、靠、要” 等思想问题的形成部分源于西部地 区农村扶贫救助体系设计的科学性不足, 这可能会在 一定程度上助长部分农村贫困人口不劳而获的消极 思想。西部地区扶贫救助体系中要针对农村贫困主体 的现实生活实际设计较为科学有效的激励机制, 不断 创新农村贫困地区扶贫工作思路和方式，如实践中部 分地区尝试采取生产奖补、劳务补贴、以工代赈等激 励性制度, 的确能够在较大程度上调动贫困对象改变 落后生产方式来提高劳动生产率的积极性。同时, 实 践中应当加强扶贫工作透明度, 防止工作不力造成虚 假贫困而引发社会不良情绪。总之，不能完全进行物 质或资金救助而盲目投入，不能让扶贫救助人员包办 代替, 不能让扶贫救助资金变成少数贫困者的生活补 贴, 不能让懒惰的贫困者投机取巧而坐享其成。此外, 国家相关部门应当积极创造条件实现西部地区农民 能够在城乡之间自由流动, 积极改革农村社会福利保 障制度，彻底解除西部地区贫困群体的后顾之忧，让 他们真切地感受市场经济和城市生活的冲击, 融入市 场经济和城市化的现代社会之中，改变其固有的生活 观念和生活方式。

\section{4. 大力发展西部地区教育事业, 加大农民 教育和科学普及力度, 增强教育扶贫的实际成 效，这是消除西部地区精神贫困的重要方法}

大力发展农村教育事业是阻断西部地区农村精 神贫困代际传递的关键所在, 是全面提高农村劳动者 素质和促进其他社会变革的有效工具。通过发展教育 事业提高西部地区农村贫困对象的基本素质，加大对 农村地区的教育投入和科学普及力度, 帮助他们努力 适应现代社会的生产与生活方式, 形成符合主流文化 特征的价值观体系, 这是消除西部地区农村贫困对象 精神贫困的重要方法。实践中应当逐步加大西部农村 地区教育经费的收入比例, 确保义务教育的全面落实, 
建立和完善适应西部地区农村发展需要的教育教学 体制, 积极进行农村地区教学内容、教学手段和方式 方法的实践探索，注重农村地区基础教育、职业教育 和成人教育三者之间的协调发展，积极构建农村教育 新模式, 为西部地区农村经济发展提供具有较高专业 技术和技能的劳动者 [10]。同时, 针对西部地区进行 的精神贫困问题, 还应当重视加强科学普及力度, 增 强教育和科技扶贫的效果。实践中可采用定期组织科 普下乡进村等系列活动, 结合农村生活实际或重大节 日开展相应的教育与科普活动, 教育广大农民群众学 会科学认知诸如生老病死等各种自然现象, 消除部分 贫困农民因缺乏基本的科学知识而导致的各种问题 或心理障碍, 通过文化教育和科普手段增强扶贫成效 以及消除西部地区的精神贫困问题。

\section{5. 充分利用西部地区独特的地缘优势，注 重发挥脱贫致富先进典型的示范作用, 发挥宗 族群体的引领作用，这是消除西部地区精神贫 困的外部源泉}

西部地区地域辽阔, 自然风景秀丽, 可充分利用 其独特的地缘优势, 注重同本地劳动力和本地资源相 结合, 充分发掘利用当地独特的自然资源和人文景观 发展旅游事业, 通过与外来人群的交流互动促进当地 农民的思维观念的积极转变, 这样可促使西部地区农 村贫困群体原有的生产与生活方式发生全面变革, 自 觉接受各种先进文化思想主动或被动的冲击影响, 通 过重新选择和主动内化实现根本转变并由此形成全 新的精神文化主体。同时, 要充分借助榜样的力量不 断完善西部地区扶贫救助的诱导机制, 充分发挥自强 自立的优秀农民和积极塑造脱贫致富过程的先进典 型以起到示范带头作用, 借助榜样的力量激发贫困对 象摆脱贫困发家致富的内部张力。如当前部分农村地 区实行的公开推选优秀村民、脱贫或致富之星等活动 方式, 用身边鲜活的先进典型激励引导农村贫困群体 转变消极等待思想, 帮助他们树立自强自立脱贫致富 的信心。当然，针对西部农村地区村民的风俗习惯和 亲缘关系特点, 充分发挥农村地区民间宗族群体对改 变农村贫困落后面貌的积极引领作用, 这也是解决西 部地区农民精神贫困的重要途径。要帮助西部地区农 村贫困群体彻底改变贫穷落后的面貌, 应当重视充分 发挥农村地区宗族群体的积极引领作用, 尤其应当做 好西部民族地区宗族群体内部核心人物的教育引导 工作, 使他们成为改变宗族群体落后面貌的领头雁。 此外, 最近几年来西部地区农村生活条件大大改善, 村民的宗族文化保护意识也不断觉醒, 许多涉及同姓 宗亲的民间组织或家族协会纷纷成立。要努力营造健 康向上的家族活动氛围, 提倡合法合规的文明宗族活 动，传承优秀的民族特色文化与家族文化，通过家族 成员之间的情感引导与相互帮扶, 特别是借助良性的 家庭或宗族與论压力可以有效避免各种传统陋习在 家庭或宗族内部滋生和蔓延, 以此带动部分贫困群体 甚至于整个家族得到较好的发展。

\section{5. 结论}

西部地区是我国扶贫攻坚的主战场, 彻底摆脱和 消除西部地区农村贫困群体的精神贫困状态是新时 代实现社会主义共同富裕必须解决的重要问题，我们 要积极创新精准精神扶贫内容, 努力推动西部地区精 准扶贫工作走向深入。只有真正从根源上改变西部地 区农村贫困群体的极其狭险的思维观念，激发其内心 积极实现脱贫致富奔小康的强烈愿望和内在需求，把 主体自身原来形成的 “要我脱贫” 消极等待思想彻 底转变为实现 “我要脱贫” 的积极动力, 这样才能帮 助他们彻底摆脱贫困状态而真正走上致富之路。

\section{致谢}

本文为西华师范大学基本科研业务费项目《西部 地区乡村振兴的文化铸魂研究: 中国传统文化与西方 心理学整合视角》(19B003)、南充市社科研究 “十三 五” 规划 2020 年度项目《乡村振兴过程中文化铸魂 的现代意蕴与路径研究》(NC2020B101) 的阶段性成果 之一。

\section{REFERENCES}

[1] Yu Dehua. (2002) On Spiritual Poverty. Philosophical Research, Vol. 12, pp. 15-20.

[2] Wu Jiaji.(2002)On the Social Structural Causes of Mental Poverty-Reflections on Mental Poverty in Underdeveloped Areas. Journal of Lishui Teachers College, Vol.1, pp. 22-25.

[3] Hang Chengzheng, $\mathrm{Hu}$ Angang. (2017) The Essence of "Mental Poverty" Phenomenon is Individual Failure-From the Perspective of Behavioral Science.Journal of Chinese Academy of Governance, Vol.4, pp. 97-103.

[4] Yu Hai.(2005)Spiritual Poverty and Cultural Construction in Underdeveloped Areas. Construction of the Old District, Vol.7, pp. 11-12.

[5] Guo Meng, Wang Yi.(2018)The Poverty Alleviation Mechanism and the Path of Poverty Alleviation of Mental Poverty in Depth Povertystricken County . Journal of Shangluo University, Vol. 2, pp. 6-12.

[6] Yu Dehua, Ma Zhaohui.(2002)A Probe into the Mentality of Spiritual Poverty and Its Elimination in Underdeveloped Areas. Studies on Mao Zedong and Deng Xiaoping Theories, Vol. 2, pp. 76-79.

[7] Wei Liping.(2017) Probe into the Inner Theory and Realization Way of Spiritual Poverty Alleviation. Social Sciences Review, Vol. 9, pp. 51-53. 
[8] Xi Jinping.(2017)Achieving a Decisive Victory in Building a Well-off Society in All Respects to the Great Victory of Socialism with Chinese Characteristics for a New Era -A Report on the 19th National Congress of the Communist Party of China. Beijing:People's Publishing House, p.51.

[9] Cheng Zhaowen.(2017)Spiritual Poverty Alleviation is the Due Meaning of Precise Poverty Alleviation. Social Sciences Review, Vol. 9, pp. 25-26.

[10] Yu Dehua, Huang Zhengen.(2003) Spiritual Poverty Eradication in the Process of Building a Well-off Society in An All-round Way in Underdeveloped Areas. Gansu Social Sciences, Vol. 6, pp. 84-87. 